University of Wollongong

Research Online

Faculty of Business - Papers (Archive)

Faculty of Business and Law

2003

Improving the efficiency of sporting venues through capacity management The case of the Sydney (Australia) Cricket Ground Trust

Paul Preda

University of Sydney

Ted Watts

University of Wollongong, tedw@uow.edu.au

Follow this and additional works at: https://ro.uow.edu.au/buspapers

Part of the Business Commons

Research Online is the open access institutional repository for the University of Wollongong. For further information contact the UOW Library: research-pubs@uow.edu.au 


\title{
Improving the efficiency of sporting venues through capacity management - The case of the Sydney (Australia) Cricket Ground Trust
}

\begin{abstract}
Capacity management seeks to improve organizational effectiveness through improved operational efficiency and reduced congestion. The article contends that there are major similarities between manufacturing organizations and sporting venues with respect to issues of capacity management. This article reports the findings of two capacity management studies undertaken at a major sporting venue in Sydney, Australia, and relates the findings to capacity management theory articulated in current capacity literature and exhibited in existing management practice. It is proposed that by understanding the welldeveloped techniques presented in the production capacity literature, venue managers may be able to identify pockets of idle capacity and bottleneck problems. This identification should facilitate the control, if not the elimination, of specific areas of waste, which in turn should remove some of the hidden costs of capacity, thereby increasing the profit potential of an organization.
\end{abstract}

\section{Keywords}

efficiency, improving, venues, cricket, ground, capacity, sporting, management, trust, case, sydney, australia

Disciplines

Business

\section{Publication Details}

Preda, P. \& Watts, T. (2003). Improving the efficiency of sporting venues through capacity management The case of the Sydney (Australia) Cricket Ground Trust. Event Management: an international journal, 8 (2), 83-89. 


\title{
IMPROVING THE EFFICIENCY OF SPORTING VENUES THROUGH CAPACITY MANAGEMENT: THE CASE OF THE SYDNEY (AUSTRALIA) CRICKET GROUND TRUST
}

\author{
PAUL PREDA* and TED WATTS $\dagger$ \\ *School of Business, Discipline of Accounting and Business Law, The University of Sydney \\ †School of Business and Informatics, Australian Catholic University
}

\begin{abstract}
Capacity management seeks to improve organizational effectiveness through improved operational efficiency and reduced congestion. The article contends that there are major similarities between manufacturing organizations and sporting venues with respect to issues of capacity management. This article reports the findings of two capacity management studies undertaken at a major sporting venue in Sydney, Australia, and relates the findings to capacity management theory articulated in current capacity literature and exhibited in existing management practice. It is proposed that by understanding the well-developed techniques presented in the production capacity literature, venue managers may be able to identify pockets of idle capacity and bottleneck problems. This identification should facilitate the control, if not the elimination, of specific areas of waste, which in turn should remove some of the hidden costs of capacity, thereby increasing the profit potential of an organization.
\end{abstract}

Sporting venues; Capacity management; Operational efficiency

Contemporary management accounting theory sees capacity as the organization's capability to transform resources into valued products and services, and, as such, represents the organization's profit potential (Hilton, Maher, \& Selto, 2000). Capacity management is the process of measuring the amount of work scheduled and then determining the necessary people, machines, and physical resources needed to accomplish it (Blackstone, 1989). In this way, capacity management can be seen as the identification of, and the resolution to, constrained resources. The underlying assumption from this view of capacity and capacity management is that in any business operation there will be capacity surpluses or shortages, and the way in which these are managed will impact upon an organization's profit. The authors contend that this view, while discussed primarily in reference to the manufacturing industry, is equally valid in the leisure/sporting industry.

\section{Capacity Management in the Literature}

Imbedded within this production view of capacity is the assumption that there is always at least one constraint on each production process that limits an 
organization's profit. The constraint may be an internal production capacity limitation, or it may be external, such as a lack of customers, logistical limitations, or availability of material. This constraint assumes there are two major types of resources: bottleneck resources and capacity constraint resources. A bottleneck resource is the activity that, while used to its fullest extent, constrains the total output that can be produced or processed. A capacity constraint resource is a resource that is not a bottleneck at present, but, if not managed properly, can develop into one as a result of technical and structural issues (Holman, 1995).

As mentioned, one type of resource is bottleneck resource. This resource assumes that production capacity is finite, restricted by one or more bottleneck operations. Contemporary management accounting theory, in the form of the theory of constraints, attempts to resolve these capacity problems by focusing on bottleneck management (Dugdale \& Jones, 1996). Closely related is the notion of throughput. Defined in most business texts as the rate the organization generates money through sales (Goldratt. 1990; Goldratt \& Cox, 1992; Ruhl, 1997), it translates easily into the sports venue literature as the rate the venue generates revenue through attendance

When translating these production concepts of capacity into concerns impacting on sporting venue management, similar issues arise. Sporting venues, like manufacturing organizations, need to determine their baseline capacity measures. As with manufacturing organizations, these capacity levels can be categorized as theoretical capacity, practical capacity, normal capacity, budgeted capacity, and actual capacity. Theoretical capacity is the optimum amount of work a process can complete using a 24-hour, 7-day operation with zero waste. It assumes that all personnel and equipment will operate at peak efficiency. Practical capacity is the level of capacity generally attainable by a process, and is theoretical capacity adjusted down for unavoidable nonproductive time, such as facility repairs and ground keeping maintenance. Normal capacity is the average, expected, utilized capacity of the facility over a defined period of time and allows for human and equipment inefficiencies and idle time from cancellations (e.g., due to inclement weather). Budgeted capacity and actual capacity are estimates of planned output versus the output actually achieved within any defined period. Budgeted capacity is a result of the planning process while actual capacity reflects what is ac- tually achieved (Dilton-Hill \& Glad, 1994: McNair \& Vangermeersch, 1998)

The Role of Capacity Management

One of the core issues of capacity management is the identification and elimination of wasted resources. McNair (1994a) identified a number of ways in which capacity is wasted. These are definitional waste (i.e., abandoning theoretical capacity), management-based waste (i.e., failure to focus on bottlenecks), technical waste (i.e... changing cost structures), and structural waste

., failure to focus on how the service is provided).

By identifying these sources of waste, actual areas and causes of idle capacity are isolated. The focus then is on the elimination of waste, as reflected in the organization's idle capacity. However, to gain maximum benefit from this, it is necessary to reconsider the way we manage capacity from the philosophy of connuous improvement. The continuous improvement model reflects a constant pursuit of perfection (the theoretical optimum), questions all assumptions relating to usage, focuses on the creation of value, builds on a process orientation that recognizes the impact of bottlenecks, and tolerates no waste (McNair. 1994a). Such a focus is equally applicable to sporting venues.

\section{Case Study}

This article reports on two capacity management studies that focused on the Sydney Cricket Ground and Sydney Football Stadium, which at the time of the study represented Sydney's largest sporting venue. The Trust, which controlled these two venues, had been experiencing difficulties with bottleneck problems at turnstiles and cashiers, as well as at franchised catering outlets within the grounds. The Thompson and Jenkins (1996) study was commissioned by the Sydney Cricket Ground Trust and was concerned with bottleneck and throughput problems. The Watts and Thompson (1996) study was also concerned with capacity problems associated with the franchised operations, together with general capacity issues impacting on the organization, in particular the identification of pockets of idle capacity. As a result, the studies had two major objectives:

1. Determining the characteristics of patron flow into and through the facility, including the identification of the major factors responsible for bottleneck problems.
2. Determining the general characteristics of operations, including the identification of areas of idle capacity responsible for capacity problems.

\section{Methodology}

The Thompson and Jenkins (1996) study established a patron flow study that determined the sequence of patron services received and the amount of time that the patron spent waiting for entry to the facility and various locations within the facility. The study timed each sequential stage of a patron's progress through the entry process and partitioned patrons into two groups: patrons who purchased tickets off site, and patrons who purchased tickets on the day at the venue.

Two factors thought to influence the overall congestion and waiting times significantly were: the method of ticket purchase and the ability of the facilities to process the entry of patrons to the grounds. Associated with this was the issue of service and waiting time at the food and beverage outlets. The Watts and Thompson (1996) study also considered issues associated with the bottleneck problems, as well as the more generic capacity problems, including the identification of pockets of idle capacity and potential structural capacity problems. This information was obtained through observation of tasks and discussions with management and staff.

\section{Descriptions of the Studies}

The Thompson and Jenkins (1966) study identified several capacity constraints, mainly driven by variations in arrival patterns. Other constraint factors included the mode of entry (prepurchased tickets or pay at turnstile), time of day, weather, and coincidental events. This study also considered capacity problems relating to franchise concessions within the Trust's area of control. This was considered necessary by Trust management, which saw such outlets as an integral part of the venue's total resources. Previously, due to a combination of poor design and unexpected demand, response times for entry and turn-a-ways from food and beverage outlets resulted in general frustration, causing problems in crowd behavior

In 1996, the Thompson and Jenkins (1996) study was augmented by a parallel capacity management study concerned with the exposure and reduction of structural waste (Watts \& Thompson, 1996). Where the Thompson and Jenkins study focused on the capacity constraints of the venue with respect to patron flow, the Watts and Thompson (1996) study considered the more generic aspects of structural waste. This focus was on the efficient use of capacity, which was reflected through the use of an efficient percentage measure between total capacity and utilized capacity.

To ensure the maximum variation of attendance patterns, attendee types, and event timing, the Thompson and Jenkins (1996) study analyzed three major events. These were: an Eagles concert with 38,000 attendees: an Australian Rules football game between the Sydney Swans and Collingwood (a Victorian team) that attracted 23,000 attendees; and a Rugby Union match between New South Wales and Natal (South Africa) with 31,000 in attendance. The Watts and Thompson (1996) study used observable data of structural practices during the same period, and data from discussions with management and ground staff.

Results

For the Thompson and Jenkins (1996) study, the average service time and waiting time was computed for each of the eight patron organizational categories identified. A measure of processing efticiency was derived from these values by dividing the service time by the sum of the service time plus waiting time. Attention was directed to those categories where service efficiency was below $50 \%$. Table 1 provides the time taken and the efficiency for each of the service categories.

The service categories that exhibited relatively low efficiency ratings, and therefore a capacity problem, were the purchase of tickets at the venue, the time taken to process these ticket holders, the time taken from entry to seating, the time taken from seating to exiting, the time spent at food outlets, and the time spent at beverage outlets. Since between $70 \%$ and $100 \%$ of patrons utilized these services, they were designated as bottleneck activities, and became the focus of further analysis.

Approximately $40 \%$ of the patrons purchased their tickets at the venue, resulting in considerable delays in both purchasing their tickets and entering the venue. The remaining $60 \%$ purchased at off-site ticket outlets, significantly reducing purchase and entry time.

The low efficiency percentage relating to time taken to be seated $(23.1 \%)$ and time taken to exit the venue $(16.7 \%)$ was the same for both groups. The other major bottlenecks identified were at food outlets, $37.5 \%$ efficient, and beverage outlets, $18.2 \%$ efficient. 
Table 1

Patron Operational Categories, Utilization and Efficiency Results

\begin{tabular}{|c|c|c|c|c|c|c|}
\hline \multirow[b]{2}{*}{ Patron Operational Category } & \multirow{2}{*}{$\begin{array}{l}\text { Percentage of } \\
\text { Patrons Using } \\
\text { Operation }\end{array}$} & \multirow{2}{*}{$\begin{array}{l}\text { Mean Operational } \\
\text { Time (in } \\
\text { Minutes-Rounded) }\end{array}$} & \multirow{2}{*}{$\begin{array}{c}\text { Mean Waiting } \\
\text { Time (in } \\
\text { Minutes-Rounded) }\end{array}$} & \multirow{2}{*}{$\begin{array}{l}\text { Mean Service } \\
\text { Efficiency Percentage: } \\
\text { Ratio of Service } \\
\text { Time to Total Time }\end{array}$} & \multicolumn{2}{|c|}{$\begin{array}{l}\text { Bottleneck } \\
\text { Problem }\end{array}$} \\
\hline & & & & & Yes & No \\
\hline Tickets purchased at grounds & $40 \%$ & 12.0 & 27.0 & 30.8 & $\mathrm{x}$ & \\
\hline Tickets purchased externally (holders) & $60 \%$ & 4.0 & 2.0 & 66.7 & & \\
\hline Time to enter grounds & & & & & & \\
\hline Ticket purchasers & $100 \%$ & 5.0 & 15.0 & 25.0 & $\mathrm{x}$ & \\
\hline Ticket holders & & 3 & & & & $\mathrm{x}$ \\
\hline Time from entry to seating & 10 & 3.0 & & 23.1 & $\mathrm{x}$ & \\
\hline Time from seating to exiting & $100 \%$ & 3.0 & 15.0 & 16.7 & $\mathrm{x}$ & \\
\hline Time spent at food outlets & $78 \%$ & 9.0 & 15.0 & 37.5 & $\mathrm{x}$ & \\
\hline Time spent at beverage outlets & $82 \%$ & 4.0 & 18.0 & 18.2 & $\mathrm{x}$ & \\
\hline
\end{tabular}

Results from the Watts and Thompson (1996) study of generic structural waste are shown in Table 2, which identifies capacity problems in the areas of ground facilities, function facilities, use of ground maintenance equipment, and the use of office equipment.

These results suggest that the capacity problems associated with structural waste occur predominantly with fixed assets.

\section{Discussion}

The patron flow study by Thompson and Jenkins (1996) provides a simple method for determining the nature of bottlenecks in a sporting venue case study. Bottlenecks result from temporal fluctuations in demand for services, variability in the staff time required to provide these services, and the physical structure of the venue The results of the three events studied were similar enough to explain the issues as a single "event," in that the same capacity issues were observed on each occasion.

Analysis of Demand Factors

In this case study, $40 \%$ of the patrons purchased their tickets at the venue, resulting in a significant bottleneck and raising managerial concern in controlling congestion. This high number of venue-purchased tickets had a flow-on effect reflected in time delays entering the venue. While such delays were not uncommon in the past, management's efforts to promote of ticket purchases had been successful, resulting in a reduction of on-site staff to handle the volume. This unexpected volume was, in part, due to the nature of the
Table 2

Examples of Generic Structural Waste

\begin{tabular}{|c|c|c|c|c|c|}
\hline \multirow[b]{2}{*}{ Structural Caregory } & \multirow[b]{2}{*}{ Utilized Capacily } & \multirow[b]{2}{*}{ Total Capacity } & \multirow{2}{*}{$\begin{array}{l}\text { Efficiency Percentage: } \\
\text { Ratio of Utilized Capacity } \\
\text { to Total Capacity }\end{array}$} & \multicolumn{2}{|c|}{ Capacity Problem } \\
\hline & & & & Yes & No \\
\hline Ground $\mathrm{f}$ & 2,080 hours per year & 8,760 ho & 23.8 & $\mathrm{x}$ & \\
\hline Function facilities & 2,380 hours per year & 8,760 hours per year & 27.2 & $\mathrm{x}$ & \\
\hline Seating capaciry & 30,666 seats $^{\mathrm{i}}$ & 45.000 seats & 68.2 & & $\mathrm{x}$ \\
\hline Ground staff & 1,152 hours per year & 1,680 hours per year & 68.6 & & $\mathrm{x}$ \\
\hline Grounds equipment & 910 hours per year & 8,760 hours per year & 10.4 & $x$ & \\
\hline Office staff & 1,500 hours per year & 1.680 hours per year & 89.3 & & $\mathrm{x}$ \\
\hline Office equipment & 1,430 hours per year & 8,760 hours per year & 16.3 & $\mathrm{x}$ & \\
\hline Management & 2,400 hours per year & 2,400 hours per year & 100.0 & & $\mathrm{x}$ \\
\hline Supplies/utilities & $100 \%$ & Bought as needed & 100.0 & & $\mathrm{x}$ \\
\hline
\end{tabular}

Average of the three observed even events, the attendance at which appeared to be spontaneous rather than planned. To help overcome this problem, the encouragement of patrons to purchase tickets off site should continue, with the possibility of offering a discount or other incentives to those who use the off-site service

The same explanation, the underestimation of patrons, could be applied to the bottlenecks associated with the food and beverage outlets. However, management pointed out that this had always been a problem, suggesting a systemic understaffing of these outlets by the franchise holder. This problem has been compounded by management's decision to ban bringing alcohol into the grounds, thereby increasing the demand at the beverage outlets. Corrections to this problem could be the inclusion in the franchise agreement a minimum number of staff at each event, or increasing the number of outlets. However, management did point out that there were contractual obligations to be considered that restricted the implementation of these suggestions.

\section{Analysis of Supply Factors}

The major impediment to the entry of patrons with venue-purchased tickets results from the entry procedures. An off-site purchased ticket has a magnetic strip, which allows immediate entry, while trust employees collect venue-purchased tickets. One significant problem arising from this is that entry access for patrons with off-site purchased tickets has been enlarged at the expense of access points for patrons with venue-purchpense of access tickets.
chased

While the supply factors associated with food and beverage outlets may be subjected to contractual obligations, the relocation of the outlets could provide some improvement in this area. At the time of the study, all outlets were clustered in one location, close to the major entry/exit route. The relocation to locations closer to the seating and the possibility of the separation of food and beverages could improve the efficiency by reducing the waiting time, the calculation of which included the time to travel to and from the outlet.

\section{Analysis of Physical Factors}

Physical factors influencing the operational categories of tickets purchased at the venue, time to enter the grounds by these patrons, and times from entry to seating and seating to exiting, in part, flow from the age and structure of the facility. While the football facility has had a major redevelopment and the cricket ground substantial refurbishment, development of various areas of the venue were constrained by heritage and $\mathrm{Na}$ tional Trust restrictions. One such area was the 19th century outer brick wall. Ideally, a greater number of entry points would improve entry flow; however, heritage restrictions prevented this. In the same way, wider entry/exit corridors could improve inflow and outflow, but in this case the historical importance of the early 20 th century construction of the facilities makes such improvements financially and physically unattractive.

The most significant finding of this study was the refining of the capacity problem to that of a bottleneck problem, and that improvements to the various bottleneck problems did not start to emerge uniil the Trust acknowledged "ownership" of the problems and took responsibility for the corrective action. In the past, it was believed that most of the problems were caused, or contributed to, by external parties (the State Government or the National Trust) and therefore not the responsibility of the Trust. The replacement of this view by one of "ownership" cleared the way for some improvements. However, before any major improvements could be implemented, the venue was replaced by the Stadium Australia, Sydney Aquatic Centre, and Sydney Show-ground complex at Homebush Bay, the venue for most of the major events of the 2000 Olympic Games.

\section{General Factors}

The establishment of the efficiency table, using specific performance categories, should reveal to venue managers the areas of idle capacity and bottleneck problems associated with their venue. The analysis of issues uncovered should provide venue managers with the information necessary to rectify the problems.

\section{Linking the Analysis to the Theory}

Both studies identified two major issues. First, capacity crises could be refined to a bottleneck resource problem. Second, the capacity problems generally resulted from management-based (bottlenecks) and structural issues.

For Thompson and Jenkins (1996), the first issue concerned the physical capacity of the venue. Their concern was with the limits imposed on the venue by management policies and by requirements of local (mu- 
nicipal) and state governments. This, in the capacity literature, is definitional waste. It is a constraint that imposes an artificial level of "normal" capacity on the venue. The effect on the organization is that it puts in place a mental set, which accepts such constraints a fixed. This causes the organization to accept as "normal" the resulting waste, or idle time. The solution is to define the venue capacity in terms of its theoretical capacity. While it may never be possible to achieve this level, it at least makes management aware of the magnitude of the wasted resource.

Another constraint identified by the Thompson and Jenkins (1996) study was arrival patterns and the bottleneck problems at turnstiles. This can be viewed in terms of management-based waste in that venue management focuses on efficiencies based on the speed of entry to the grounds. While this appears logical, it ignores the fact that the capacity is defined and controlled by bottleneck resources. The bottleneck resource-the number of turnstiles that accommodated venue-purchased tickets-limited the volume that could enter the grounds. Capacity, therefore, should be defined as the maximur flow into the grounds given the bottleneck resource.

Other constraints identified conform to the notion of technical waste. Such waste is reflected in chang ing cost structures caused by increasing fixed costs a technology replaces labor. In this instance, waste is created because the new assets are managed at the predetermined practical capacity, a level of capacity already burdened with in-built inefficiencies and waste. To manage these new assets, it is essential to understand the capacity of the resources. What becomes important is the realization that capacity may change dramatically over time as a result of technological changes. In the case of the Sydney Cricket Ground Trust, these technological changes included off-sit ticket sales, the introduction of "swipe" turnstiles, an the redeployment of staff resources. The impact of these technological changes imposes an ongoing monitoring of the fixed assets introduced, together with a continuous reassessment of the practical capacity of resources and the levels of utilization (Dilton-Hill \& Glad, 1994).

The problem of structural waste was also evidenced at the Sydney Cricket Ground Trust venues by the Wats and Thompson (1996) study. The essence of structural waste is that the capacity of some resources will always be underutilized because the resource is constrained within a system that has less effective capacit
(McNair, 1994b). In the case of the Sydney Cricket Ground the use of facilities. Once resources begin to be used, the manner in which capacity can be wasted increases. In the majority of cases, the predetermined "normal" or "practical" capacity is seldom reached. This is because the practical capacity number used by most organizations is based on a 35-hour week rather than on 168-hour week In the case of most sporting venues, the capacity number is based on something less than a 35 -hour week. When such a large percentage of available capacity is assumed away, it is difficult to generate profits. This embedded waste is seldom considered or measured, and represents a permanent loss of potential profits.

\section{Conclusions}

The purpose of this article was to inform venue managers, possibly unfamiliar with the theoretical and practical concepts of capacity management, of issues relating to capacity and bottleneck problems through two specific case studies. At the same time, the case studies linked the problems identified back to the capacity management literature.

Both the Thompson and Jenkins (1996) study and the Watts and Thompson (1996) study identified several capacity issues with respect to a large sporting venue, in particular the problem of bottlenecks. This article has demonstrated that these issues parallel general capacity concerns in the production/manufacturing industry, and articulated in the management accounting literature. By identifying these capacity and bottleneck problems, venue managers can put in place processes that should eliminate the bottleneck and reduce structural waste.

However, the identification of these similarities does invite criticism. The obvious differences raised when it is suggested there are similarities between capacity planning in production/manufacturing organizations and sporting venues is (1) sporting venues do not produce a physical product, and (2) sporting venues do not have inventory to contend with. Both of these arguments are fallacious. First, the absence of a physical product does not relieve an organization of the obligation to manage its resources, nor does it detract from the accountability of resource managers. Given that capacity is the value-creating ability of an organization, and that this ability takes form in a wide va- riety of resources (McNair \& Vangermeersch, 1998), the issue of capacity management is fundamental to the survival of the sporting venue. Second, the contemporary production/manufacturing organization, through a variety of management accounting techniques (e.g., just-in-time production), is attempting to minimize, if not eliminate, inventory.

Therefore, in both types of organizations the process capacity, that is, the ability to transform resources into valued products and services, is governed by underlying constraints of the function, which may be physical (e.g., a process) or invisible (e.g., government policy or training). To resolve this, it is clear that both organizational types should focus on managing the various constraints of their particular environments through adopting a system view. This requires viewing the organization as a set of interdependent processes that are linked to transform inputs into outputs (Hilton et al., 2000). In so doing, it should be possible to identify the bottleneck that moves around the organization. This would provide a practical mechanism for improving the use of constrained processes. Acceptance and implementation of these techniques by sporting venue managers must improve their efficiency and consequently their bottom line.

\section{Acknowledgment}

The authors acknowledge the constructive comments of the participants at the 25th Annual Congress of the European Accounting Association, Copenhagen, Denmark, 2002, and the Fifth International Management mark, 2002, and the Fifth International Management
Control Systems Research Conference, London, England, 2001. The article also benefited from suggestions made on an earlier version by participants at the 7th European Congress of the European Association for Sports Mangement, Thessaloniki, Greece, 1999.

\section{References}

Blackstone, J. (1989). Capacity management. Cincinnati, $\mathrm{OH}$ APICS-South Western Publishing.

Dilton-Hill, K. G., \& Glad, E. (1994). Managing capacity. In B. J. Brinker (Ed), Emerging practices in cost management (pp.
H3.1-3.8). New York: Warren, Gorham \& Lamont.

Dugdale, D., \& Jones, C. (1996, April). Accounting for throughput. Management Accounting - London, 74(4), 24-29.

Goldratt, E. M. (1990). The theory of constraints. Croton-onHudson, NY: North River Press.

Goldratt, E. M., \& Cox, J. (1992). The goal. Croton-on-Hudson, NY: North River Press.

Hilton, R. W., Maher, M. W., \& Selto, F. H. (2000). Cost management: Strategies for business decisions. Boston: Irwin McGraw-Hill.

Holman, J. S. (1995, January). ABC vs TOC: It's a matter of time. Management Accounting - US, LXXVI, $37-40$.

McNair, C. J. (1994a). The hidden cosis of capacity. In B. J. Brinker (Ed.), Emerging practices cost management (pp. H1.1-1.13). New York: Warren, Gorham \& Lamont.

McNair, C. J. (1994b). The profit potential: Taking high performance to the bottom line. Essex Junction, VT: Oliver Wight Publications.

MeNair, C. J., \& Vangermeersch, R. (1998). Total capacity management: Optimising at the operational, tactical, and strategic levell. Boston: St. Lucie Press.

a agement

Thompson, S, \& Jenkins, M. (1996). Capacity planning and venue mangernen. Unpublished working paper School of Accounting/School of Leisure and Tourism. Faculty of Business, University of Technology, Sydney.

Watts, E. W., \& Thompson, S. (1996). The impact of capacity costs on venue facilities. Unpublished working paper, School of Accounting/School of Leisure and Tourism. Faculty of Business, University of Technology, Sydney. 